\begin{tabular}{|c|c|}
\hline Citation & $\begin{array}{l}\text { Kim Loyens, (2013), } \\
\text { Towards a custom-made whistleblowing policy. Using grid-group } \\
\text { cultural theory to match policy measures to different styles of peer } \\
\text { reporting } \\
\text { Journal of Business Ethics, } 114(2), 239-249 \text {. }\end{array}$ \\
\hline Archived version & $\begin{array}{l}\text { Author manuscript: the content is identical to the content of the published } \\
\text { paper, but without the final typesetting by the publisher }\end{array}$ \\
\hline Published version & http://dx.doi.org/10.1007/s10551-012-1344-0 \\
\hline Journal homepage & http://www.springer.com/social+sciences/applied+ethics/journal/10551. \\
\hline \multirow[t]{2}{*}{ Author affiliation } & Kim Loyens, Leuven Institute of Criminology, Faculty of Law, KU Leuven \\
\hline & $\underline{\text { (University of Leuven), Belgium }}$ \\
\hline \multirow[t]{2}{*}{ Author contact } & kim.loyens@law.kuleuven.be \\
\hline & $+32(0) 16329452$ \\
\hline IR & https://lirias.kuleuven.be/handle/123456789/346691 \\
\hline
\end{tabular}

(article begins on next page) 


\title{
Towards a custom-made whistleblowing policy. Using grid-group cultural theory to match policy measures to different styles of peer reporting
}

\begin{abstract}
To be effective, whistleblowing policies should be adapted to the organisational culture. They need to be custom-made and not follow a one-size-fits-all logic, specifically when they are installed to stimulate responsible peer reporting, a highly sensitive and value-laden type of whistleblowing. This paper attempts to illustrate that grid-group cultural theory could help to construct a whistleblowing policy by linking reporting styles to the organisational culture. First, we will identify four types of policy measures that are hypothesized to be effective in four types of organisational culture. Second, we develop the hypothesis that certain organisational cultures can induce peer reporting that is harmful for the organisation. The whistleblowing policy can then be used as a catalyst for cultural change.
\end{abstract}




\section{Introduction}

Peer reporting is a specific type of whistleblowing that occurs "when group members go outside their group to report a member's misconduct" (Treviño \& Victor, 1992: 39). It is considered more delicate and value-laden than other forms of reporting, because it implies complex within-group pressures (Treviño et al., 1992: 39) and often leads to reporters being labelled a snitch or a traitor (de Graaf, 2010: 769). Setting out a policy to encourage responsible reporting of peers' misconduct is thus very difficult and complex. This paper argues that whistleblowing policies should be custom-made, because not all policy measures are suitable for every organisation. It hypothesizes that, depending on the organisational culture in the organisation and the whistleblowing behaviour that is prevalent different types of measures should be taken. On the basis of the grid-group cultural theory (GGCT) framework different policy measures will be matched to different styles of peer reporting, going a step further than the traditional whistleblowing literature that lists general factors that impact the decision to blow the whistle.

This paper consists of three parts. The first part gives an overview of the general whistleblowing literature, and particularly focused on the lists of factors that are found to explain reporting. In the second part, grid-group cultural theory will be presented as an alternative framework to not just list factors, but to identify different reporting styles and the mechanisms that are hypothesized to explain their occurrence in an organisation. The third part will illustrate the hypothesis that depending on which reporting styles are dominant different measures need to be taken to stimulate preferable reporting behaviour. In other words, the hypothesis is developed that a whistleblowing policy should be custom-made in the sense that it is adapted to the prevalent reporting style(s) in an organisation.

\section{Peer reporting in the whistleblowing literature}

Peer reporting is often considered a specific type of internal whistleblowing (Treviño et al., 1992). The literature shows a variety of many different definitions and typologies of whistleblowing. The disagreements in defining the concept have led to a number of approaches to explain its occurrence. This part attempts to provide an overview of the various ways the topic has been addressed in the literature.

\subsection{Defining and explaining whistleblowing}

Whistleblowing can be defined in various ways. The literature shows a lack of consensus about what the concept means and what its main components are. Based on Jubb (1999) and Vandekerckhove (2006: 22), seven elements of ambiguity in the whistleblowing definitions can be identified: act, actor, outcome, motive, subject, target and recipient. Clearly the most cited definition is that of Near and Miceli (1985: 4) who describe whistleblowing as "the disclosure by organisation members (former or current) of illegal, immoral or illegitimate practices under the control of their employers, to persons or organisations that may be able to affect action".

Empirical research in this tradition, mostly quantitative, has led to the conclusion that a number of individual, situational and organisational factors can have an impact on whistleblowing intentions or behaviour (see e.g. King \& Hermodson, 2000; Near \& Miceli, 1996; Jos et al., 1989). It is not our intention to go into detail about the results, but three important remarks should be made. First, these individual, situational and organisational factors may of course have an interacting effect, meaning that individuals who observe misbehaviour might combine various reasons to decide whether or not to report (King \& Hermodson, 2000: 325). Most studies have, however, led to the 
conclusion that situational and organisational factors explain more variation in the decision to blow the whistle than do individual factors (Rothwell \& Baldwin, 2007; Miceli, Near \& Schwenk, 1991). Second, although interesting, the empirical findings in different studies do not seem to be completely consistent or conclusive (Near \& Miceli, 1996: 515). Hence continuing research is necessary. Third, there seems to be a twofold gap in the empirical research so far. On the one hand, most studies, using surveys or vignettes, respectively focus on what people say they did in the past or what they would do in hypothetical situations, and - due to distortion, forgetting and social desirability bias that is not necessarily the same as what they actually did or would do when faced with a particular situation (Miceli, Near \& Dworkin, 2009: 386; Miceli \& Near, 1992: 41-42). More importantly although quantitative studies are interesting to identify correlations between variables that affect whistleblowing - they do not suffice to fully capture the processes that underlie the decision to report (Dworkin \& Baucus, 1998: 1283). Hence, qualitative research is needed to gain more insight into the underlying mechanisms that could explain whistleblowing processes (Maesschalck \& Ornelis, 2003: 539).

\subsection{Peer reporting as a special type of internal whistleblowing}

Peer reporting is often considered a specific type of internal whistleblowing and can be defined as occurring "when group members go outside their group to report a member's misconduct" (Treviño et al., 1992: 39). It is, however, essential to treat peer reporting as a special case of whistleblowing, because it has at least three important particularities that need to be underlined. First, the general whistleblowing literature often speaks of employees who question their superiors' behaviour, which fits into the idea of upward control (Graham, 1986), while peer reporting is about lateral control because an individual then reports the misconduct of another group member to authorities outside the group (Treviño et al., 1992: 40). Second, following the logic of Treviño and Victor (1992), peer reporting often involves "complex within-group pressures" (p. 39), because "groups can be expected to prefer handling misconduct themselves" (p. 40). The third characteristic is intertwined with the second. Going outsides one's group to report misbehaviour of peers could be considered a different kind of loyalty conflict than going against a supervisor or collective misconduct in the broader organisation. Group loyalty is an important group norm (Katz \& Kahn, 1978), and often seems to be stronger than loyalty to the organisation itself (de Graaf, 2010: 769). When having to choose between the protection of integrity versus the protection of colleagues, keeping silent in the interest of the group is mostly preferred to being labelled a traitor or a snitch. Peer reporting does, however, not always threaten the stability of the group, but can sometimes even be a way to protect the group, for example if the misbehaviour harms norms, values and agreed upon ethical standards of the group (Greenberger, Miceli \& Cohen, 1987; Treviño et al., 1992: 41). If group members, on the other hand, somehow benefit from overlooking misconduct in the group, they may oppose peer reporting (Near et al., 1985).

This all leads to the conclusion that reporting on peers is more delicate and value-laden than any other form of whistleblowing. Combined with the fact that peer reporting often evokes stronger and more emotional reactions than other types of reporting, it is clear that the decision to do so is even more difficult (Treviño et al., 1992: 40; King et al., 2000: 312). The question is, then, whether the existing theoretical frameworks and empirical findings concerning internal and external whistleblowing could unproblematically be applied to peer reporting. In other words, even though peer reporting is often considered a special type of internal whistleblowing, it is difficult to know 
which conclusions could be adopted from the general whistle-blowing literature to explain decisions to report or not to report colleagues' misbehaviour. Because empirical studies that specifically focus on peer reporting are limited, further research is necessary to reach more decisive conclusions (Victor, Treviño \& Shapiro, 1993: 259-260; de Graaf, 2010: 770).

\section{Peer reporting from a GGCT perspective}

We now return to the central topic of interest in this paper, which is attempting to set out a policy to encourage responsible peer reporting. To achieve this, a theoretical framework is needed that provides insight into the processes that underlie the decision to report on colleagues' misbehaviour. Although the general whistleblowing literature, discussed above, can be an interesting source of inspiration, it is not completely sufficient for at least two reasons. First, it only lists factors that correlate with reporting without giving insight into the mechanisms that explain the decision to report. Second, it has predominantly focused on decisions whether or not to report superiors' misbehaviour, leading to a gap in the literature concerning peer reporting. Hence, we will broaden the lens by applying the more general grid-group cultural theory (further referred to as GGCT), following Morrison (2009: 345) who states that "it may be time for some new theoretical models or perspectives that will inspire scholars to think about whistleblowing in a new way and thereby help to generate the added research energy that seems to push this area further".

In this part, we will first illustrate that GGCT is both a typology and a theory by, on the one hand, explaining how the two dimensions ('grid' and 'group') can be combined into four types, and on the other hand, by listing the three causal claims. Second, we will explain how GGCT could be used to identify different styles of peer reporting and the mechanisms that explain their occurrence.

\subsection{Two dimensions, four organisational forms}

GGCT was originally developed by the anthropologist Mary Douglas (1982), but subsequently applied in different research domains, like public administration (Hood, 1998), political science (Thompson, Ellis \& Wildavsky, 1990; Jensen, 1998) and organisational ethics (Mars, 1982; Maesschalck, 2004; Loyens, 2012). The framework provides a typology for a number of organisational forms, based on two dimensions: 'grid' and 'group'. 'Grid', on the one hand, refers to the extent to which an individual's life is bounded by externally imposed rules, prescriptions, and stratification. The more 'grid', the less of life is open to individual negotiation (Thompson et al., 1990: 5). 'Group', on the other hand, stands for the incorporation of an individual into a bounded unit of actors or the extent to which individual choice is constrained by group choice (Hood, 1998: 8). The greater the incorporation, the more individual choice is subjected to group determination and the more of individuals' behaviour is constrained by the group.

When these two dimensions are combined in a matrix, four organisational forms can be identified (see Table 1), each of them high or low on the two dimensions: hierarchy (high grid, high group), egalitarianism (low grid, high group), individualism (low grid, low group), and fatalism (high grid, low group). Each type will be briefly described below. 
Table 1: Two dimensions and four types in GGCT

\begin{tabular}{|l|l|l|}
\hline High grid & \multicolumn{1}{|c|}{ Low group } & \multicolumn{1}{|c|}{ High group } \\
& $\begin{array}{l}\text { FATALISM } \\
\text { a system of rules that is beyond their } \\
\text { control. } \\
\text { Suspicion towards other human beings; } \\
\text { you do not know what to expect from } \\
\text { them. } \\
\text { Conflicts can be dealt with if you are } \\
\text { lucky; just try to survive. } \\
\text { Risk of inertia and the unwillingness to } \\
\text { plan ahead or take necessary measures. }\end{array}$ & $\begin{array}{l}\text { HIERARCHY } \\
\text { Central idea: Rules prescribe roles and } \\
\text { responsibilities within a well-defined } \\
\text { group. } \\
\text { Human beings are born sinful but can be } \\
\text { redeemed by good institutions. } \\
\text { Conflicts can be dealt with by referring } \\
\text { to rules and authority. } \\
\text { Risk of misplaced trust in procedural } \\
\text { rules and authority. }\end{array}$ \\
\hline $\begin{array}{l}\text { INDIVIDUALISM } \\
\text { Central idea: Individuals are } \\
\text { entrepreneurs that operate in a } \\
\text { competitive environment. } \\
\text { Human beings are self-seeking and } \\
\text { stimulated to strive for self-interest. } \\
\text { Conflicts can be dealt with by one-on- } \\
\text { one negotiation and bargaining. } \\
\text { Risk of chaos due to a lack of } \\
\text { cooperation and tendency to put the } \\
\text { individual above the common good. }\end{array}$ & $\begin{array}{l}\text { EGALITARIANISM } \\
\text { Central idea: } \text { Everyone is equal and } \\
\text { should cooperate for the welfare of the } \\
\text { group. } \\
\text { Human beings are born good but can be } \\
\text { corrupted by evil institutions. } \\
\text { Conflicts can be dealt with by group } \\
\text { negotiation in order to reach consensus. } \\
\text { Risk of inefficient decision making and } \\
\text { even disruption of the group by } \\
\text { scapegoating ('blaming') or removing } \\
\text { the bad apple }\end{array}$ \\
\hline
\end{tabular}

First, in hierarchy rules prescribe roles and positions, while the group attachment provides legitimacy for the organisational stratification (O'Riordan \& Jordan, 1999). Hence, status is derived from one's position in a well-defined group (Breed, 2007: 70). The central assumption is that each individual has its place and role with accompanying responsibilities. Individual interests are subjected to the collective good (Thompson et al., 1990: 35) and conflicts can only be solved by referring to legitimate rules and authority. Because problems can, however, not always be solved with rules and procedures and the world is not entirely controllable, this organisational culture is not without limitations (e.g. rule-fetishism) (Schwartz, 1991: 765).

Second, in egalitarianism not formal rules and procedures are central, as in hierarchy, but deliberation and group negotiation in order to reach consensus (Rayner, 1986: 581; Smullen, 2007: 54). The group boundaries are clearly set, leading to an us-versus-them attitude, and distrust to outsiders (Breed, 2007: 71). Within the group, solidarity is highly valued and individual interests are subjected to the welfare of the group or the higher good (Rayner, 1986: 581). The central assumption is that all individuals in the group are equal (Breed, 2007: 71) and decisions should be made collectively, possibly leading to informal rules (Jensen, 1998). Consensus is, however, not always feasible, which could lead to deficient decision making, disruption in the group (Jensen, 1998: 122) or even schism (Schwartz, 1991: 765). Practices like scapegoating ('blaming') or removing the bad apple can also be used when group members are considered to not serve the interests of the group. 
Third, individualism is a cultural type with market-like characteristics, implying a competitive environment where everyone works hard to develop skills that are necessary to get results (Rayner, 1986: 576). Individuals are considered strategic entrepreneurs who operate within performanceoriented organisations where status is derived from personal skills and efforts (Hood, 1998: 109-118). An individualistic culture stimulates the strive for self-interest (Verweij et al., 2006: 820) and competition rather than cooperation (Rayner, 1986: 581). Ego-focused networks are developed where tit-for-that strategies are used to make deals that are profitable for all actors. Conflicts are dealt with by bargaining practices and one-on-one negotiation. Undiluted individualism could, however, lead to anarchy (Schwartz, 1991: 765) or an aggressive struggle for survival, as Thompson and colleagues (1990: 87) say: "Without some modicum of hierarchy to make rules and to enforce contracts, unmitigated self-regulation leads to chaos."

The fourth type, fatalism, is often considered a passive way of life, distinguished from the three active ones in GGCT. Central in this cultural type is that individuals are (or feel) highly bound by a system of rules that is beyond their control, and against which they cannot undertake collective action, due to a lack of group affiliations (Vaughan, 2002: 416). Other human beings are looked at with suspicion, because you never know what to expect from them (Thompson et al., 1990: 35). The fatalistic world is considered a lottery, characterized by unpredictability and chance, possibly leading to desperation (Schwartz, 1991: 765). Hence, trying to survive is the main coping strategy (O'Riordan et al., 1999: 87). Despite its negative connotation, fatalism can be a valuable perspective to cope with the unavoidable impotence to find solutions for every single problem. Hence, fatalism can release individuals from the burden of the world's problems on their back by introducing some form of acquiescence.

\subsection{Causal propositions in GGCT}

As stated above, GGCT is not only a typology, but also a theory. Specifically, we deduce three causal claims. The first causal claim is that the four cultural types, explained above, shape the behaviour and values of staff members or, in other words, "[a]s people organise, so they will behave" (Thompson et al., 1990: 97). This has been referred to as the compatibility proposition. Applied to peer reporting, the organisational culture has an impact on peer reporting, in such a way that a higher grid/group bound organisational culture leads to higher grid/group bound peer reporting styles, as will be explained later.

The second causal claim is the requisite variety proposition. It implies that each type needs the other "to define itself against" (Maesschalck, 2004: 31), and therefore, "all four [cultural] types are at least potentially and usually actually, always present" (Maesschalck, 2004: 31). Because the four types are thus present in all agencies, the main concern is the 'dose' of each type in a specific organisation (Thompson et al., 1990; Hendriks, 2004). Combined with the first causal claim, this leads to the following hypothesis in this paper: the relative dose of the four peer reporting styles is associated with similar doses of the corresponding organisational culture. In other words, if a certain organisational culture is dominant in an organisation, it can be expected that a certain peer reporting style will be dominant as well.

Closely linked to the requisite variety proposition, the third causal claim states that each cultural type has its own built-in weaknesses or blind-spots that, taken separately, might lead to negative consequences or excesses (Hood, 1998). Hierarchy could for example lead to rule-fetishism, egalitarianism to schism, individualism to anarchy and fatalism to desperation (Schwartz, 1991: 765). By, however, combining or balancing organisational types 'clumsy institutions' are created that 
prevent the constant shift between imperfect solutions of organisational design, leaving room for all voices in the discussion (Thompson \& Rayner, 1998). This proposition has been referred to as sociocultural viability $(6,2003: 398)$.

\subsection{Four types of (not) reporting colleagues' misconduct in GGCT}

This part aims to illustrate how the GGCT framework, already applied in many disciplines and in different research settings, can also shed some light on reasons why staff members (do not) blow the whistle on peers' misbehaviour. Inspiration is drawn from the work of Anthony Evans (2008), who for the first time used this theory in the domain of whistleblowing. His contribution is twofold. On the one hand, he managed to translate the cultural types into whistleblowing terms, identifying one reporting style and three styles of deciding not to blow the whistle. On the other hand, he demonstrated how GGCT can be used to explain the failure of most management tools in dealing with dissent, making the link between organisational factors and whistleblowing behaviour.

The approach in this paper is somewhat different, because it is based on the assumption that in all four cultural types different styles of (not) reporting can be identified. This disagreement is mainly due to conceptual differences, in the sense that Evans' (2008) definition of whistleblowing is stricter than the definition of peer reporting in this paper. Being counterintuitive, this statement needs some clarification. Although peer reporting is often considered a subtype of the more general whistleblowing behaviour (that is addressed in Evans' work), it seems that Evans' (2008) interpretation of whistleblowing is very specific. His definition of a whistleblower is restricted to individuals with two key traits: (1) "a degree of empowerment - a willingness to challenge people in a position of authority [...] weak grid" and (2) "a sense of righteousness - a belief in self-sacrifice for the common good [...] high group" (p. 270). This interpretation logically leads to the conclusion that whistleblowing is an egalitarian act, which is in accordance with the interpretation of Hood (1998: 26) who considers whistleblowing one possible egalitarian response to public-management disasters, next to participation and communitarianism. This paper attempts to broaden this perspective by trying to identify other styles of reporting and not reporting. As there are four ways of organising and four types of organisational culture, arguably, there are also four ways of deciding to blow the whistle on colleagues' misbehaviour or not, each of them being more or less grid/group bound (see table 2). Each of them will be explained below. 
Table 2: Four types of (not) reporting colleagues' misconduct in GGCT

\begin{tabular}{|c|c|c|}
\hline & Low group & High group \\
\hline High grid & $\begin{array}{l}\text { FATALISM } \\
\text { Peer reporting: You don't have a lot of } \\
\text { choice, because you could get punished } \\
\text { if you don't report. What if they find out } \\
\text { you knew about it? } \\
\text { No peer reporting: It is not any of my } \\
\text { business and being a snitch would only } \\
\text { make life more difficult. }\end{array}$ & $\begin{array}{l}\text { HIERARCHY } \\
\text { Peer reporting: Reporting is in line with } \\
\text { orders, rules and procedures, and it is } \\
\text { your responsibility to do it; escalating } \\
\text { concerns through the chain of } \\
\text { command. } \\
\text { No peer reporting: It is not your role to } \\
\text { report; you are a team player who does } \\
\text { not want to rock the boat. }\end{array}$ \\
\hline Low grid & $\begin{array}{l}\text { INDIVIDUALISM } \\
\text { Peer reporting: Strategic, opportunistic } \\
\text { behaviour aimed at personal benefits } \\
\text { (e.g. career planning). } \\
\text { No peer reporting: Opportunistic } \\
\text { behaviour aimed at personal benefits; } \\
\text { keep quiet for your own sake (e.g. } \\
\text { negative deal-making, precautions for } \\
\text { the future). }\end{array}$ & $\begin{array}{l}\text { EGALITARIANISM } \\
\text { Peer reporting: We are the pure ones } \\
\text { who should ban the bad ones or the } \\
\text { 'rotten apple' (sense of righteousness); } \\
\text { behaviour harms the group. } \\
\text { No peer reporting: Unethical behaviour } \\
\text { is not framed as unethical; group loyalty } \\
\text { is more important. }\end{array}$ \\
\hline
\end{tabular}

First, the hierarchical style of peer reporting is characterized by the idea that reporting is in line with orders, rules and procedures. Individuals feel it is their role and responsibility to blow the whistle when they see a colleague misbehave. The high 'grid' aspect in this behavioural style refers to the idea that procedures need to be followed and responsibility needs to be taken. Because there is also high 'group', the organisation members endorse this viewpoint. Everyone plays his part and agrees upon the unequal distribution of power and responsibility in the organisation. Hence, procedures, roles and responsibilities are considered to be part of a fair system that should be maintained, if necessary even at the expense of the individual. If one would like to report on peers' misconduct in a hierarchical organisational culture, one has to follow the procedures of escalating concerns through the chain of command. This idea of whistleblowing in the sense of following duty is connected to what Near and Miceli (1996: 511) call role-prescribed forms of reporting, referring to instances where individuals consider it their role responsibility to report wrongdoing. Hierarchy also implies that there is a sense of fairness about the system and internal procedures, which is in accordance with the findings in empirical research that individuals are more inclined to report misconduct when they perceive the organisation to be more just (Near et al., 1996: 511), or in other words when they think the organisation has a higher intensity of procedural and retributive justice (Victor et al., 1993; Goldman, 2001).

The hierarchical decision not to blow the whistle on colleagues' misbehaviour is inspired by the idea that it is not your role or your responsibility to do so. There may be individuals within the organisation with job descriptions that include whistleblowing, like for example an internal auditor, but yours does not. Evans (2008: 270) states that the hierarchical decision not to blow the whistle can also be induced by the perception that the individual in the organisation has to be a "team-player [who] would not want to rock the boat". 
Second, there is also an egalitarian style of peer reporting. This type of whistleblowing is induced by the idea of uprightness and virtuousness. This type of whistleblower is convinced that he is a pure one that should ban the bad ones, because one rotten apple can spoil the whole barrel. He is also willing to self-sacrifice for the common good. This is the type of whistleblowing that Evans (2008: 270) refers to: acts that express empowerment and a sense of righteousness. The reporting act is in accordance with a higher moral code (Hood \& Jackson, 1991) or a sense of justice (de Graaf, 2010: 772). A slightly less noble egalitarian way of reporting is the disclosure of one group member's misconduct because the behaviour harms the group. Empirical findings suggest that peer reporting intentions will be higher when the misbehaviour is perceived as harmful for the group (e.g. Treviño \& Victor 1992; Victor et al. 1993). The latter has also been put forward by Christine Horne (2001) who claims that cohesion might strengthen social control. Applied to the topic of this paper, this could imply that group members are sometimes encouraged by other members to report on the misconduct of deviants in the group. Although a group member will then be punished, the reporter would still be praised for his/her behaviour because he/she managed to uphold the general group norms (see also: Chan 2003; Westmarland 2005; de Graaf 2010: 773).

Egalitarianism can also manifest itself in decisions not to reveal peers' misconduct. This can occur in at least two ways. On the one hand, individuals can abstain from peer reporting because they want to remain loyal to their colleagues. This means that in the balancing of various values in the peer reporting dilemma, loyalty towards one's peers outweighs loyalty towards one's supervisor or higher management. The 'group' aspect in the GGCT framework is highly emphasized here. Following rules and procedures or respecting the chain of command (grid) are less important than sticking together as a team (group). An informal silence code is an illustration of this type of egalitarianism, where loyalty and solidarity among staff members lead them to perceive peer reporting as a betrayal of their colleagues. On the other hand, not blowing the whistle could also be induced by the fact that unethical behaviour is not framed as unethical. If breaking the rules leads to beneficial results, then organisation members often do not consider it wrong, following the end justifies the means principle. The reality of the observer may also be reshaped, when being told by other group members that the behaviour is actually accepted by the group and part of the way things are done within the team (Greenberger et al., 1987; King et al., 2000).

Third, the individualistic style of peer reporting can be defined as strategic and opportunistic behaviour aimed at personal benefits. This type of whistleblowing implies the consideration of the pros and cons of disclosing peers' misbehaviour and if the gains outweigh the losses then the rational choice is made to blow the whistle. The importance of a cost-benefit analysis when deciding to blow the whistle or not has already been suggested by several authors (e.g. Miceli \& Near 1992: 147; Gundlach, Douglas \& Martinko 2003: 112). Keil et al. (2010: 791) speak of "benefit-to-cost differential", which is "the net difference between the perceived costs and expected benefits of whistleblowing, as perceived by a potential whistleblower". High (perceived) risks of retaliation may, for example, cause organisation members to believe that the costs of blowing the whistle are too high (Farrell \& Petersen, 1982; Dozier, 1988). The reasoning in this type of peer reporting can also be inspired by competition between peers, illustrated by whistleblowing to search for promotion by getting in good terms with a supervisor (King et al., 2000: 312), to avoid being sanctioned for one's own share in the misconduct by snitching on other colleagues that were involved (Punch, 1985: 156) or to settle a personal score (Near et al., 1996). 
In the individualistic style not to report, strategy and opportunism are also emphasized. Observers of misconduct who make a rational calculation could come to the conclusion that whistleblowing is too costly, too risky and not at all beneficial (Evans, 2008: 270). Hence, they decide to keep quiet for their own sake. Near and Miceli (1985) already suggested that individuals may oppose whistleblowing if they in any way benefit from overlooking misconduct. A case in point is negative deal-making in which colleagues, who know about each other's misconduct, implicitly cut a deal not to snitch, mutually protecting each other's reputation and career (e.g. "the blue wall" in the police, Skolnick 2002). Another example is the situation where staff members retain from reporting because they make precautions for the future; a colleague whose misbehaviour he observed might become an important ally in the future. Peer reporting might in that situation not be the most opportunistic strategy.

The fourth and final style of peer reporting that can be deduced from the GGCT framework is the fatalistic one. Both the decision to report and the decision not to report are then induced by the fatalistic idea of protecting oneself in a hazardous and unpredictable environment. Because behaviour in fatalistic organisational cultures is often considered to be more or less passive - as in Evans' (2008: 270) statement that "[t]he fatalist would keep their head down" - it is expected that peer reporting is not as likely as in hierarchical, egalitarian and individualistic environments. Hence, most observers of misconduct would bury their heads in the sand because they convince themselves that it is not any of their business. Moreover, being a snitch would only make their life more difficult. Although it is probably less obvious to claim that an individual in a fatalistic environment would even consider reporting misconduct, empirical research mentions whistleblowing behaviour that would fit the fatalistic type (Rothschild \& Miethe, 1999: 119). This kind of reporting is then classified as defensive "in the sense that they feared that if they did not report and the malfeasance was eventually discovered, that it would be blamed on them" (de Graaf, 2010: 774). Hence, whistleblowers feel they don't have a lot of choice, because they could get punished if supervisors would find out that they knew about it but tried to cover it up. Especially in fatalistic organisations reporting can be highly risky, because you never know what to expect from your bosses. The fatalistic style of reporting is nicely illustrated by Jubb (1999: 82):

"[...] whistleblowing is a hazardous mode of dissent involving high risk to the individual and his/her dependents. It demands moral courage, given the typical nature of whistleblowers' complaints. This is not to say that whistleblowing is necessarily proper conduct since the motives of the whistleblower and the circumstances of the action are crucial to its justification. One motive may be to escape complicity so as to protect personal integrity and the ability to live with oneself."

\section{A custom-made whistleblowing policy}

The part above explained that peer reporting styles can be linked to the organisational culture. This concurs with the general whistleblowing literature in which organisational culture is considered one of the situational variables that influence reporting (Maesschalck \& Ornelis 2003: 543; Miceli \& Near 1992). Although authors in this tradition emphasize that a whistleblowing policy should be custommade and adapted to the organisational culture, most recommendations appear to be rather general as if they apply a one-size-fits-all logic. Specifically, they recommend policy efforts to create an open culture in which people can give feedback on each other's work and in which leaders show self- 
reflection and willingness to change on the basis of staff members' reports of organisational misconduct. These kinds of policy recommendations resemble the egalitarian perspective, in which 'group' is high and no 'grid' is needed to regulate staff members' interactions. Following the logic of GGCT, this is, however, only one of the four perspectives to address the topic of whistleblowing in an organisation. This paper hypothesizes that an egalitarian whistleblowing policy will be much more effective in organisations where egalitarian reporting styles are dominant, which is more likely in an egalitarian organisational culture (see above). In, say, an individualistic organisational culture, where staff members will only blow the whistle after a cost-benefit analysis, egalitarian measures might not be so effective because the latter require high 'group'. Hence, because there are four styles of peer reporting, that can be explained by four types of organisational culture, it is hypothesized that there are also four ways to construct a policy that stimulates responsible reporting.

This part will first give an overview of the four types of whistleblowing policies. It illustrates which measures are, according to this hypothesis, most effective in each of the four organisational cultures. However, certain low 'group' policies (i.e. fatalistic and individualistic) could lead to undesirable excesses. Therefore, the second part illustrates how they can be complemented with high 'group' policy measures leading to a custom-made whistleblowing policy that promotes cultural change.

\subsection{Four types of whistleblowing policies}

As there are four reporting styles (see above), it can be hypothesized that there are also four ways to construct a whistleblowing policy. Each of these will be explained below.

A hierarchical whistleblowing policy is characterised by high 'group' and high 'grid'. It consists of a fair system (Near et al., 1996: 511) with clear rules, endorsed by all staff members. This policy respects the chain of command and highlights managers' responsibility in dealing with organisational misconduct. The procedure prescribes that when confronted with peers' misbehaviour, staff members should report it to their direct supervisor, who decides whether to deal with it himself or to take other steps, like for example reporting it to his own boss, or referring the case to a formal (internal or external) body that is responsible for investigating that specific type of misconduct. If, however, the supervisor himself is involved in the misbehaviour, then one should go directly to the supervisor's boss or the responsible formal body. These types of measures work best in hierarchical organisations where peer reporting occurs because staff members are inclined to follow rules and procedures (high grid), and consider it their responsibility to act upon peers' misconduct (high group). The latter can be stimulated by implementing specific clauses in the code of ethics, which emphasize that whistleblowing is part of all organisation members' role-responsibility (see also: Treviño \& Victor 1992; Wren 1985).

An egalitarian whistleblowing policy is characterised by high 'group' and low 'grid'. Informal rules are thus preferred above formal procedures. Because all staff members are considered equal, the chain of command is less important than in the hierarchical whistleblowing policy. Organisation members are stimulated to openly give feedback on each other's misbehaviour and if that is not feasible or effective other reporting channels are possible, like for example a confidential advisor or trusted representative. Another egalitarian option is the installation of a representative committee that receives complaints about staff members' misbehaviour and gives advice on which course of action 
would be in the organisation's best interest. These types of measures are most suitable in an egalitarian organisational culture where peer reporting occurs in the interest of the group.

In an individualistic whistleblowing policy, both 'group' and 'grid' are low. Typical policy measures are aimed at creating incentives for blowing the whistle and ways to reduce the costs. As for the first, Evans (2008: 275) unambiguously speaks about financial incentives. He states that, although it is not common to use them, giving a financial reward to whistleblowers - in a sort of 'bounty model' (see e.g. Callahan \& Dworkin 1992) - might be effective to stimulate reporting. Less direct rewards include beneficial consequences for the workplace when the wrongdoing stops, like for example an improved atmosphere (Near et al., 1985). When staff members have the impression that effective action will be taken on the basis of their report and this will improve the work climate, peer reporting is more likely. Notwithstanding potential benefits, blowing the whistle on colleagues' misbehaviour often carries high costs, like the risk of retaliation against the reporter (Keil, Tiwana, Sainsbury \& Sneha, 2010; Miceli, Rehg, Near \& Ryan, 1999). Reducing these costs, by for example offering the possibility to report in an anonymous or confidential way, can promote peer reporting in an individualistic organisational culture. Also adjusting misperceptions of possible negative consequences by correct communication about procedures to protect whistleblowers can have a beneficial impact. Although the measures mentioned above (i.e. attempts to increase the benefits and reduce the costs) could be effective in all organisational cultures, they work best in an individualistic one, because staff members make a cost-benefit analysis when they decide whether or not to report (see above).

A fatalistic whistleblowing policy is characterised by low 'group' and high 'grid'. Typical measures are hotlines that staff members can use to anonymously report peers' misbehaviour. Although these socalled 'snitch lines' would also work in an individualistic culture, because of the reduced risk of retaliation (see above), they seem to be explicitly designed for a fatalistic organisational culture. Hotlines can be used to nurture the already existing atmosphere of distrust and suspicion among staff members in which peer reporting occurs in a defensive way. If an atmosphere is created where everyone is a potential snitch, staff members who know about colleagues' misbehaviour will be stimulated to tell their side of the story before someone else (wrongfully?) accuses them.

\subsection{Clumsy whistleblowing policies to promote responsible peer reporting}

Although four types of peer reporting have been explained above - both high 'group' (i.e. hierarchical and egalitarian) and low 'group' (i.e. individualistic and fatalistic) - whistleblowing in the literature is often considered high 'group' behaviour. As explained above, Evans (2008: 270) speaks of "a sense of righteousness" and "a belief in self-sacrifice for the common good" as key traits of the whistleblower. Near and Miceli state that whistleblowing behaviour only occurs when there is some "reasonable supposition of success" (1996: 510), which does not include reporting for purely vindictive reasons as can be the case in the individualistic style. We agree that high 'group' reporting styles are more preferable than the low 'group' styles, because the latter could lead to a number of undesirable excesses. In an extremely individualistic culture, peer reporting could become a weapon that is used in malicious settlements, where reporters for example exaggerate complaints to settle a personal score. In a fatalistic culture, characterised by suspicion and distrust, there is a risk of over reporting out of fear to be accused of complicity, possibly undermining stability and trust within groups (King et al., 2000). 
Whistleblowing policies that induce these low 'group' reporting styles (i.e. individualistic and fatalistic) could thus stimulate these excesses. Notwithstanding potential risks, these low 'group' measures can be highly valuable for at least two reasons. First, although the reporter's motives in the low 'group' reporting styles are not always admirable, they are in fact of no importance. What matters in whistleblowing policies is that supervisors and managers obtain as much information as possible about misconduct in the organisation (Lewis, 2001: 173). If staff members are only willing to give information about their colleagues' misconduct in exchange for a reward (as is the case in an individualistic organisational culture), perhaps management should consider this. Second, following the grid-group cultural theory logic, policies that are adapted to the dominant organisational culture are more effective, especially in the short term, than policies that are not.

However, if low 'group' reporting styles become excessive in an organisation, high 'group' whistleblowing policy measures can serve as catalysts for cultural change. This is a logical consequence of the idea of socio-cultural viability $(6,2003$ : 398) or the 'clumsiness proposition' (Maesschalck, 2004), as it has also been referred to (see above). Because each cultural type has its own built-in weaknesses, they should be combined with other cultural types. Applied to the topic of this paper, if peer reporting in an organisation is mainly individualistic and fatalistic (or low group), then certain hierarchical and egalitarian policy measures (high group) can be taken to counterbalance possible excesses. A hierarchical body could, for example, be installed to perform a pre-investigation and filter out the most significant complaints, thus discouraging over reporting in fatalistic environments. The result is a 'clumsy', but custom-made, whistleblowing policy with both high 'group' and low 'group' measures that could transform the organisational culture. However, two remarks need to be made. First, one has to keep in mind that these measures will only be effective in the long term, because initiatives for cultural change inevitably lead to resistance and, therefore, take time. Second, implementing high 'group' whistleblowing policy measures to transform a low 'group' organisational culture will only be effective when they are integrated in an ethics management program (Maesschalck et al., 2003: 557) or a broader human resource policy. In low 'group' organisational cultures, the 'group' dimension can, for example, be stimulated by measures like $360^{\circ}$ appraisals, open-plan office space (Evans, 2008: 276), effective internal communication channels, management's commitment to integrity and fair procedures of personnel evaluation. In other words, a whistleblowing policy, to be effective, should not be considered a mere tool to stimulate responsible reporting, but one instrument in a broader change project.

\section{Conclusion}

This paper hypothesized that not every whistleblowing policy is suitable for every organisation. It tried to illustrate how practitioners could benefit from applying grid-group cultural theory when implementing a whistleblowing policy that is adapted to the organisational culture. This theory argues that depending on the organisational culture and the reporting styles that are induced by it, different policy measures will be effective. In organisations where, for example, the hierarchical style of peer reporting is dominant, a different type of policy needs to be implemented than in organisations where the whistleblowing behaviour is characterized by egalitarianism. Because low 'group' peer reporting styles, like the individualistic and fatalistic ones, could lead to undesirable excesses (see above), high 'group' whistleblowing policies could be implemented to promote cultural change. The result is a 'clumsy', but custom-made, whistleblowing policy with both high 'group' and low 'group' measures that could effectively stimulate responsible peer reporting. 
Trying to reach a workable balance or a successful dosage of the four GGCT types is in practice, however, extremely challenging. This results from the open systems perspective in GGCT. In open systems theory, an organisation is seen as "a set of subsystems [e.g. managerial, psycho-social and goals \& values subsystem] interacting with each other" (Berrien, 1968: 32) that is influenced by its broader environment (Harrison \& Shirom, 1999: 46). The impact of the environment is, in open systems theory, captured by looking at the 'environmental suprasystem', which not only consists of the close environment like stakeholders, resources and customers, but also the general environment like the economy, the political system and the broader societal culture (Harrison et al., 1999: 45). Organisations could thus be considered a precarious system in which changes in one subsystem or in the environmental suprasystem could have an impact on the organisational system as a whole. Applied to the topic of this paper, societal changes and political reforms could have a drastic impact on the whistleblowing policy. Custom-made whistleblowing policies should thus also take these broader environmental factors into account. Although these aspects have not been discussed in this paper, GGCT could also be used to capture these broader societal factors, being applicable at all levels of social scale and all domains of human life (Verweij et al., 2006: 821; Thompson, 1996: 48).

GGCT, however, only offers the necessary pieces of the puzzle, while policymakers and managers have the duty to combine the pieces so a nicely displayed puzzle appears. Further research is thus needed to identify the exact mix or the 'dose' of whistleblowing instruments that is most effective in specific organisations. This could be done by action research in which on the basis of an analysis of reporting behaviour (in qualitative or quantitative research) specific whistleblowing measures are implemented, after which the impact of these measures can be studied. Other options are case studies in various organisations to analyse the impact of different types of whistleblowing measures (i.e. instruments of the four GGCT types) on reporting behaviour. Future research should, however, try to anticipate on two risks of applying GGCT.

First, using a theory-driven approach to study policy measures implies the risk of theoretical blindness, leading to rigidity in the sense that empirical data are 'forced' or 'manipulated' to fit the framework (i.e. the four types of GGCT), as illustrated by Lofland et al. (2006: 217): "Don't become too locked in or committed to a particular theoretical perspective or line of argument too early in the analysis process". This risk can be limited by constantly keeping an open mind to empirical data that do not seem to fit the framework (i.e. reporting styles that do not fit the four GGCT reporting styles or whistleblowing measures that do not fit the four GGCT whistleblowing measures).

Second, there is the related issue of falsifiability of GGCT. According to Thompson, Ellis and Wildavsky (1990), GGCT would be falsified if empirical research finds that different institutional contexts (i.e. whistleblowing policies in this paper) generate similar cultural behavioural styles (i.e. peer reporting styles in this paper) or if similar institutional contexts lead to different cultural worldviews (Thompson et al., 1990: 273). Although the author believes that GGCT has gained sufficient plausibility by its application in various empirical studies in different domains (see above), there is a possibility that GGCT would be falsified in specific contexts. Because the hypotheses of Thompson et al. (1990) are very generally formulated and are thus, as such, difficult to falsify, future research should actively look for ways to falsify the theory to test its applicability in particular organisations. This could, first, be done by actively looking for alternative hypotheses as a form of theory triangulation (Denzin, 1978). When alternative hypotheses are confirmed, the theory can be adapted and improved, but when alternative hypotheses are falsified, the original hypothesis is corroborated. Second, it is important to look for deviant cases, which is a stronger version of the search for falsification. When 
confronted with data that seem to contradict the theory, one needs to first find out whether these data really refer to a deviant case or are the result of faulty data collection or badly performed data analysis (Maesschalck, 2010: 140-142). Falsifying information concerning the combination of whistleblowing instruments and reporting styles could thus lead to completely refuting the theoretical framework or adapting it.

To conclude, although GGCT seems promising to construct custom-made whistleblowing policies, future research is essential to test its applicability in specific organisational settings, because a theoretical model is only as strong as its practical applicability. 


\section{References}

6, P. (2003). Institutional Viability: a Neo-Durkheimian Theory. Innovation, 16 (4): pp. 395-415.

Berrien, F. K. (1968). General and social systems. New Brunswick, NJ: Rutgers University.

Breed, K. (2007). Bestuurscultuur en strategie. Een onderzoek naar de cognitieve kaart van topambtenaren. Den Haag: Sdu uitgevers.

Callahan, E. S. \& Dworkin, T. M. (1992). Do good and get rich: Financial incentives for whistleblowing and the False Claims Act. Villanova Law Review, 37: pp. 273-336.

Chan, J. (2003). Fair cop: learning the art of policing. Toronto: University of Toronto Press, 342 p.

de Graaf, G. (2010). A report on reporting: why peers report integrity and law violations in public organizations. Public Administration Review, 70 (5): pp. 767-779.

Denzin, N. K. (1978). The research act: A theoretical introduction to sociological methods. New York: McGraw-Hill.

Douglas, M. (1982). In the active voice. London: Routledge Kegan \& Paul, 320 p.

Dozier, J. B. (1988). Is whistle-blowing helping behavior? A laboratory study of team members' reporting of an unethical team leader. Doctoral dissertation. Ohio State University, Columbus.

Dworkin, T. M. \& Baucus, M. S. (1998). Internal vs. external whistleblowers: a comparison of whistleblowing processes. Journal of Business Ethics, 17: pp. 1281-1298.

Evans, A. J. (2008). Dealing with dissent: whistleblowing, egalitarianism, and the republic of the firm. Innovation: the European Journal of Social Sciences, 21 (3): pp. 267-279.

Farrell, D. \& Petersen, J. C. (1982). Patterns of political behavior in organizations. The Academy of Management Review, 7 (3): pp. 403-412.

Goldman, B. M. (2001). Toward an understanding of employment discrimination claiming: an integration of organizational justice and social information processing theories. Personnel Psychology, 54: pp. 361-386.

Graham, J. W. (1986). Principled organizational dissent: A theoretical essay. In B. M. Staw \& L. L. Cummings (Eds.), Research in organizational behavior (pp. 1-52). Greenwich (CT): JAI Press.

Greenberger, D. B., Miceli, M. P. \& Cohen, D. J. (1987). Oppositionists and group norms: The reciprocal influence of whistle-blowers and coworkers. Journal of Business Ethics, 6 (7): pp. 527-542.

Gundlach, M. J., Douglas, S. C. \& Martinko, M. J. (2003). The decision to blow the whistle: a social information processing framework. Journal of Management Review, 28 (1): pp. 107-123.

Harrison, M. I. \& Shirom, A. (1999). Organizational diagnosis and assessment: bridging theory and practice. Thousand Oaks, CA: Sage, $486 \mathrm{p}$.

Hendriks, F. (2004). The poison is the dose: or how 'more egalitarianism' may work in some places but not in all. Innovation, 17 (4): pp. 349-361.

Hood, C. \& Jackson, M. W. (1991). Administrative argument. Aldershot: Dartmouth.

Hood, C. (1998). The art of the state. Culture, rhetoric, and public management. Oxford: Clarendon Press.

Horne, C. (2001). The enforcement of norms: Group cohesion and meta-norms. Social psychology quarterly, 64 (3): pp. 253-266.

Jensen, L. (1998). Cultural theory and democratizing functional domains. The case of Danish housing. Public administration, 76 (1): pp. 117-139.

Jos, P. H., Tompkins, M. E. \& Hays, S. W. (1989). In praise of difficult people: a portrait of the committed whistleblower. Public Administration Review, 49 (6): pp. 552-561. 
Jubb, P. B. (1999). Whistleblowing: a restrictive definition and interpretation. Journal of Business Ethics, 21 (1): pp. 77-94.

Katz, D. \& Kahn, R. (1978). The social psychology of organizations. New York: John Wiley.

Keil, M., Tiwana, A., Sainsbury, R. \& Sneha, S. (2010). Toward a theory of whistleblowing intentions: a benefit-to-cost differential perspective. Decision Sciences, 41 (4): pp. 787-812.

King, G. \& Hermodson, A. (2000). Peer reporting of coworker wrongdoing: a qualitative analysis of observer attitudes in the decision to report versus not report unethical behavior. Journal of Applied Communication Research, 28 (4): pp. 309-329.

Lewis, D. (2001). Whistleblowing at work: On what principles should legislation be based? Industrial Law Journal, 30 (2): pp. 169-193.

Lofland, J., Snow, D. A., Anderson, L., \& Lofland, L. H. (2006). Analyzing social settings. A guide to qualitative observation and analysis. Belmont, CA: Thompson Wadsworth.

Loyens, K. (2012). Integrity secured. Understanding ethical decision making among street-level bureaucrats in the Belgian Labor Inspection and Federal Police. Katholieke Universiteit Leuven, Leuven.

Maesschalck, J. \& Ornelis, F. (2003). Een interdisciplinaire analyse van de klokkenluidersproblematiek in de openbare sector. Tijdschrift voor bestuurswetenschappen en publiekrecht, 58 (8): pp. 535557.

Maesschalck, J. (2004). Towards a public administration theory on public servant's ethics. Katholieke Universiteit Leuven, Leuven.

Maesschalck, J. (2010). Methodologische kwaliteit in het kwalitatief onderzoek. In T. Decorte \& D. Zaitch (Eds.), Kwalitatieve methoden en technieken in de criminologie (pp. 120-145). Leuven: Acco.

Mars, G. (1982). Cheats at work. An anthropology of workplace crime. Aldershot: Ashgate.

Miceli, M. P. \& Near, J. P. (1992). Blowing the whistle: The organizational and legal implications for companies and employees. New York: Lexington Books.

Miceli, M. P., Near, J. P. \& Dworkin, T. M. (2009). A word to the wise: How managers and policymakers can encourage employees to report wrongdoing. Journal of Business Ethics, 86 (3): pp. 379-396.

Miceli, M. P., Near, J. P. \& Schwenk, C. R. (1991). Who blows the whistle and why? Industrial and Labor Relations Review, 45: pp. 113-130.

Miceli, M. P., Rehg, M., Near, J. P. \& Ryan, K. C. (1999). Can laws protect whistle-blowers? Results of a naturally occuring field experiment. Work and occupations, 26 (1): pp. 129-151.

Morrison, E. W. (2009). Book review: Whistle-blowing in organizations (Miceli, Near \& Dworkin, 2008). Administrative Science Quarterly, 54 (2): pp. 344-346.

Near, J. P. \& Miceli, M. P. (1985). Organizational dissidence: the case of whistle-blowing. Journal of Business Ethics, 4 (1): pp. 1-16.

Near, J. P. \& Miceli, M. P. (1996). Whistle-blowing: myth and reality. Journal of Management, 22 (3): pp. 507-526.

O'Riordan, T. \& Jordan, A. (1999). Institutions, climate change and cultural theory: Towards a common analytical framework. Global Environmental Change, 9 (2): pp. 81-93.

Punch, M. (1985). Conduct unbecoming: The social construction of police deviance and control. London: Tavistock.

Rayner, S. (1986). Management of radiation hazards in hospitals: Plural rationalities in a single institution. Social Studies of Science, 16 (4): pp. 573-591. 
Rothschild, J. \& Miethe, T. D. (1999). Whistle-blower disclosures and management retaliation. The battle to control information about organization corruption. Work and occupations, 26 (1): pp. 107-128.

Rothwell, G. R. \& Baldwin, J. N. (2007). Whistle-blowing and the code of silence in police agencies. Crime and Delinquency, 53 (4): pp. 605-632.

Schwartz, B. (1991). A pluralistic model of culture. Contemporary Sociology, 20 (5): pp. 764-766.

Skolnick, J. H. (2002). Corruption and the blue code of silence. Police Practice and Research, 3 (1): pp. 7-19.

Smullen, A. J. (2007). Translating agency reform. Rhetoric and culture in comparative perspective. Erasmus Universiteit Rotterdam, Rotterdam.

Thompson, M. \& Rayner, S. (1998). Risk and governance part I: The discourses of climate change. Government and Opposition, 33 (2): pp. 139-166.

Thompson, M. (1996). Inherent relationality: An anti-dualist approach to institution. Bergen: LOSCentre Report 9608.

Thompson, M., Ellis, R. \& Wildavsky, A. (1990). Cultural Theory. Boulder: Westview Press.

Treviño, L. K. \& Victor, B. (1992). Peer reporting of unethical behavior: a social context perspective. Academy of Management Journal, 35 (1): pp. 38-64.

Vandekerckhove, W. (2006). Whistleblowing and organizational social responsibility: A global assessment. Hampshire (England): Ashgate Publishing, $351 \mathrm{p}$.

Vaughan, B. (2002). Cultured punishments: the promise of grid-group theory. Theoretical Criminology, 6 (4): pp. 411-431.

Verweij, M., Douglas, M., Ellis, R., Engel, C., Hendriks, F., Lohmann, S., Ney, S., Rayner, S. \& Thompson, M. (2006). Clumsy solutions for a complex world: The case of climate change. Public administration, 84 (4): pp. 817-843.

Victor, B., Treviño, L. K. \& Shapiro, D. L. (1993). Peer reporting of unethical behavior: The influence of justice evaluations and social context factors. Journal of Business Ethics, 12: pp. 253-263.

Westmarland, L. (2005). Police ethics and integrity: breaking the blue code of silence. Policing and Society, 15 (2): pp. 145-165.

Wren, T. E. (1985). Whistle-blowing and loyalty to one's friends. In W. C. Hefferman \& T. Stroup (Eds.), Police ethics: Hard choices in law enforcement (pp. 25-43). New York: John Jay. 